a result of contraction or phosphorylation/dephosphorylation processes remains obscure. In secretory tissues the universal response to raised cytosolic calcium is the release of secretory products stored in subcellular vesicles by fusion of vesicle and plasma membrane. Creutz et al. (J. biol. Chem. 253, 2858 ; 1978) report the isolation of a 47,000 molecular weight protein which promotes the close association of adrenalin-containing granules isolated from adrenal glands. Contacts resembling the apposition of secretory granule membrane with plasma membrane before fusion, form reversibly in the presence of calcium ions above about $10 \mu \mathrm{M}$. It was not established whether the granuleaggregating protein itself bound calcium, or became bound as a result of a calcium binding event on the granule itself. The latter alternative is more consistent with the observations of Gratzl et al. (Biophys. biochim.
Acta. 470, 45; 1977). These authors claim that aggregation and fusion of isolated secretory granules from several tissues occurs in the presence of $10 \mu \mathrm{M}$ calcium. Magnesium ions could not substitute for calcium in this process. A protein, rather than a lipid calcium-binding component, is implicated, since liposomes made from the lipids found in secretory granules do not aggregate or fuse at such low calcium concentrations.

The ability of the TnC-like proteins to confer calcium sensitivity upon enzymic processes, perhaps by combining with a common regulatory protein subunit, potentially accounts for the multiple intracellular effects of calcium. However, it is still premature to claim the uniqueness of these proteins as calcium receptors in nonmuscle cells, and the characterisation of other recently identified members of this class of calcium-binding proteins is eagerly awaited.

\title{
The enigma of poxviruses
}

from Arie Zuckerman and Charles Rondle

THE global eradication of smallpox is probably the greatest public health achievement of the 20th century. Eradication was possible because of the availability of a highly effective vaccine prepared from vaccinia virus. Yet one of the most controversial aspects of vaccination is the origin of vaccinia virus, and in particular whether it is derived from smallpox or cowpox. It has also been suggested that vaccinia might have arisen as a hybrid between these viruses. It appears, however, that vaccinia virus is most closely related to cowpox. Phylogenetically, the whole group probably derives from one common ancestor and its differentiation must be connected with the domestication of animals by the first agricultural settlers of the human race.

The second reason for the success of the smallpox eradication programme is that smallpox is a human disease with no known animal reservoir or insect vector. But nevertheless, problems remain since natural poxvirus infection of nonhuman primates does occur (see 241, 425; 1973).

Monkeypox virus was first identified in 1958 during an outbreak of a vesicular skin disease in captive Cynomolgus monkeys in Copenhagen (von Magnus et al., Acta Path.

Arie Zuckerman is Professor and Head of the Department of Medical Microbiology and Charles Rondle is Senior Lecturer, at the London Schon! of Hygiene and Tropical Medicine. microbiol. scand. 46, 156; 1959). The distribution of the rash was similar to that of smallpox in man and the virus was recognised as a poxvirus by its structural features under the electron microscope and by its serological relationship to vaccinia virus. By 1969 , monkeypox virus had been isolated from captive nonhuman primates, or from their organs, on 10 occasions, including one isolation from an anteater which temporarily shared a cage with an infected orang-utang. Between 1970 and the middle of 1978, human cases of monkeypox were reported from West and Central Africa with five $(15 \%)$ deaths, a mortality rate similar to smallpox in that region. Furthermore, most cases clinically resembled smallpox. The prospect of the spread of monkeypox from man to man was alarming, but in the event possible secondary transmission only occurred in two cases--of 55 susceptible family contacts only $2(3.6 \%)$ acquired the infection, and there have been only 33 recognised cases among over 200 million people in a period of more than 8 years. But the natural host and vector of monkeypox virus remain unknown, despite the fact that there are reports of 'smallpox' in monkeys as long ago as 1767 (Arita \& Henderson Bull. Wld Hlth Org. 39, 277; 1968).

Whitepox virus is a more worrying puzzle. This virus was first identified in a Dutch laboratory in September 1964 during routine processing of Asian
Cynomolgus kidney tissues (Gispen \& Brand-Saathof, Bull. Wld Hlth Org. 46, 585 ; 1972) and could not be distinguished at the time from smallpox virus by laboratory tests. The name 'whitepox' was given to the isolates because in contrast to monkeypox they produced small dense white pocks on the chorioallantoic membrane of the developing chick embryo. Between 1971 and 1973, this virus was isolated on four occasions from primate kidney tissues derived from a chimpanzee and a sala monkey, and from two rodents, Mastomys natalensis and a squirrel-like rodent captured in Zaire (Marennikova et al. Bull. Wld Hlth Org. 46, 61; 1972; Acta Virol. 20, 80; 1976). Experimentally, a whitepox virus inoculated into Ceropithecus aethiops monkey caused a generalised rash and illness. Whitepox virus still cannot be distinguished from smallpox virus by laboratory tests (Fenner Prog. med. Virol. 23, 1; 1977), and it therefore remains both a puzzle and a threat. The fact that no infections with smallpox-like virus have occurred in Zaire during the 7 years since the last smallpox case was identified is at least reassuring. It does seem, therefore, that animal poxviruses are not a threat to the global eradication of smallpox, but the need for constant surveillance and laboratory studies continues.

Marennikova and Shelukhina (see this issue of Nature, page 291) now report that whitepox viruses isolated

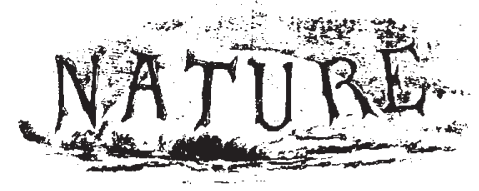

\section{A hundred years ago}

THE Daily News Quebec correspondent telegraphs as follows:- "After long study and many experiments Prof. Bell has made an important discovery in connection with the telephone. It is well known that the telephone has been a comparative failure in England on account of the fatal induction generated by the contiguity of other wires. Prof. Bell has discovered simple and efficacious means whereby not only is induction prevented, but the clearness and force of the telephonic vocalisation greatly increased. Prof. Bell tells me that practical demonstration of the importance of the discovery will be given in London as soon as the necessary preliminaries are complete." We give this statement as published in in the Daily News, though it must be received with some caution.

From Nature 19, 14 November, 46; 1878. 